\title{
ПРОЦЕСС ЛЕКСИЧЕСКОГО ЗАИМСТВОВАНИЯ НА СОВРЕМЕННОМ ЭТАПЕ РАЗВИТИЯ РУССКОГО ЯЗЫКА: ЗА И ПРОТИВ
}

\section{THE PROCESS OF LEXICAL BORROWING AT THE PRESENT STAGE OF DEVELOPMENT OF THE RUSSIAN LANGUAGE: PROS AND CONS}

\section{O. Beljaeva}

Summary: This article describes the features of the process of lexical borrowing at the present stage of the development of the Russian language. The author considers several points of view. Supporters are trying to understand the reasons for the appearance of borrowed words in the Russian language, and believe that such words enrich the Russian language. Opponents of clogging the Russian language with foreign words, they propose to replace all such words with their own, originally Russian. It is emphasized that the problem is not only that foreign words appear uncontrollably in our language, but also in how they are understood, interpreted and in what sense are used by people. The article analyzes the data of various sociological studies, the purpose of which was to reveal the attitude of people to the borrowing of foreign words into Russian speech, as well as awareness of the meaning of these words.

Keywords: borrowed words, Russian word, influence of foreign words, culture of speech, national wealth.

\section{Введение}

Л ексический и словарный запас - это богатство любого языка в мире. С течением времени, с ходом истории каждый язык видоизменяется и увеличивается. Поэтому язык часто сравнивают с живым растущим организмом. Мы знаем, что все живое не может остаться без изменения и движения. На разных этапах своего существования язык вбирает в себя всё новые слова, отбрасывает ненужные, переделывает сложные слова в более простые и точные. Вряд ли наш человек из XIX века, смог бы понять нашу речь. Мы работаем на компьютере, распечатываем на принтере, боимся фастфуда, вечером смотрим ток-шоу.

Язык всегда должен отвечать своей главной функции - быть удобным в употреблении для людей, которые им пользуются. То есть, быть точным, ёмким, выразительным.

Цель исследования: определение влияния заимствованных слов на развитие русского языка.

\author{
Беляева Олеся Николаевна \\ старший преподаватель, Тихоокеанский \\ Государственный Университет, г. Хабаровск \\ 003835@pnu.edu.ru
}

Аннотация: В данной статье описываются особенности процесса лексического заимствования на современном этапе развития русского языка. Автором рассматривается несколько точек зрения. Сторонники пытаются разобраться в причинах появления заимствованных слов в русском языке, и считают, что такие слова обогащают русский язык. Противники засорения русского языка иностранными словами, предлагают заменить все такие слова своими, исконно русскими. Акцентируется, проблема не только в том, что иностранные слова бесконтрольно появляются в нашем языке, но и в том, как они понимаются, интерпретируются и в каком смысле используются людьми. В статье проведен анализ данных различных социологических исследований, целью которых было выявить отношение людей к заимствованию иностранных слов в русскую речь, а также осведомленность в значении этих слов.

Ключевые слова: заимствованные слова, русское слово, влияние иноязычных слов, культура речи, национальное богатство.

Актуальность данной темы вызвана тем, что судьба русского языка - тема, которая волнует любого современного человека. Заимствование иноязычных слов - это непрерывный процесс, который происходит постоянно. В последнее время всё чаще происходит появление новых понятий и иностранных слов-синонимов, которые заменяют наши русские слова. Кто-то радуется этому, ну а кто-то огорчается? Бороться с изменениями или принимать их?

У данной проблемы есть как сторонники, так и противники. В связи с недавними изменениями в правилах правописания и орфографии русского языка появилось много вопросов, так как глобальных изменений в нашем языке не было уже давно. Будет создан проект, над которым трудятся лучшие академические умы нашего государства. Изменения коснутся в первую очередь как раз-таки заимствованных слов, которые будут внесены и закреплены в орфографический словарь. Сторонники пытаются разобраться в причинах появления заимствованных слов в русском языке. Они считают, что заимствованные слова обогащают русский язык. Противники 
засорения русского языка иностранными, предлагают и вовсе заменить такие слова своими, исконно русскими.

Русский язык - плод многовекового творчества труда, который крепко связан со славной историей нашего государства в течение многих веков. Он являет собой поразительное социальное, культурно-историческое национальное богатство. Язык - одна из главнейших составляющих сохранения нации. Упрощая и уничтожая язык, мы упрощаем и уничтожаем себя.

С самых ранних стадий английский язык вступил в контакт с рядом различных иностранных языков. Взаимодействие носителей английского языка с иностранными неизбежно повлияло структура английского языка. Наиболее заметное влияние этих языков было в словарном запасе, хотя были затронуты и другие уровни языковой системы. Основное внимание в этой статье уделяется лексическому влиянию латинского, греческого и других языков из германской семьи.

Активное заимствование слов, пришедших из английского языка и его американского варианта, вместо русских начало проявляться с 50-х годов 20 века и было названо великим русским филологом В.В. Виноградовым «американобесием». Удивительно точное определение! Особенно «американозасилие» усилилось в 1990-х годах и причиной тому стала повсеместная ориентация на Запад во всех сферах жизни общества. Все это оставило и продолжает оставлять серьезный и мрачный след в великом русском языке. А вдруг, таким образом и у нас не стал явью страшный бред о переходе на латиницу, во многих странах это уже есть, например в Турции.

Давайте вспомним слова Ивана Сергеевича Тургенева: «Берегите чистоту языка, как святыню! Никогда не употребляйте иностранных слов. Русский язык так богат и гибок, что нам нечего брать у тех, кто беднее нас» [2].

Конечно же, на этот счет существует несколько точек зрения. Многие лингвисты и филологи, а также специалисты считают, что «русский язык - это живой язык, что русский язык немыслим без заимствованных слов, и это очень легко доказать» $[1,5]$. Достаточно привести примеры слов, которые нам кажутся исконно русскими, но на самом деле таковыми не являются. Люди принимают решения по-разному в зависимости от того, владеют ли они родным или вторым языком. Учащиеся, говорящие на двух языках, получают важные академические успехи: всесторонний обзор исследований молодых ученых подтверждает, что широко доступные общественные программы, помогают учащимся, говорящим на двух языках, добиться важных академических успехов. В разные эпохи в русском языке обычно преобладали заимствования из какого-то одного языка. Двуязычие улучшает слух, усиливает внимание: согласно недавнему исследованию, богатый опыт двуязычных людей с языком «настраивает» их слуховую нервную систему и помогает им манипулировать лингвистическими способами, которые улучшают внимание и рабочую память. [3].

Стоит упомянуть в данной статье и влияние интернациональных слов на наш родной язык. В последние десятилетия в наш язык приходят слова в основном из английского языка, и связаны они с современными техническими устройствами и информационными технологиями (компьютер, ноутбук, смартфон, онлайн, веб-сайт). Нарастающее и все более активное расширение глобальных контактов приводит к значительному увеличению международного словарного запаса. Все языки зависят в своих изменениях от культурной и социальной матрицы, в которой они действуют, и различные контакты между народами являются частью этой матрицы, отраженной в словарном запасе. Интернациональные слова играют особенно важную роль в различных терминологических системах, включая лексику науки, промышленности и искусства. Этимологические источники этого словаря отражают историю мировой культуры. Темпы изменений в технологиях, политической, социальной и художественной жизни значительно ускорились в 20 веке, как и темпы роста международного словарного запаса. Несколько примеров сравнительно новых слов, появившихся благодаря прогрессу науки, будет достаточно, чтобы проиллюстрировать важность международного словаря: алгоритм, антенна, антибиотик, кибернетика, ген, генетический код, микроэлектроника и т.д. Интернациональный словарный запас также растет из-за постоянного внедрения экзотических заимствованных слов, таких как анаконда, бунгало, крааль и т.д. Они происходят из самых разных источников. Интернациональные слова не следует смешивать со словами общего индоевропейского происхождения, которые также составляют своего рода общий фонд европейских языков. Этот слой имеет большое значение для учителя иностранного языка не только потому, что многие слова, обозначающие абстрактные понятия, являются интернациональными, но и потому, что он должен знать наиболее эффективные способы показать точки сходства и различия между такими словами, как control - контроль; generl - генерал; industry - индустрия или magazine - магазин и т.д. обычно называют «ложными друзьями переводчика». Обработка международных слов на уроках английского языка была бы односторонней, если бы учитель не обращал внимание своих учеников на распространение английской лексики на другие языки. Когда дело доходит до изучения языка, последние исследования показывают, что вашим лучшим активом может быть изучение заимствованной лексики. Здесь уместно сказать о неоспоримом преимуществе. Ведь говорение на другом языке может замедлить развитие заболеваний, связанных с нервной системой: люди, которые говорят на нескольких языках и у которых развиваются сопутствующие заболевания, 
как правило, делают это на пять лет позже, чем те, кто говорит на одном языке, согласно исследованию, проведенному исследователями из разных университетов. «Эти данные свидетельствуют о том, что двуязычие может иметь более сильное влияние на такие процессы, чем любые доступные в настоящее время лекарства. Это позволяет взаимосвязи между двуязычием и познанием стать одним из наших высших приоритетов.

Следует упомянуть хотя бы некоторые из русских слов, заимствованных из английского и многих других языков и, следовательно, международных: балалайка, царь, кремль, советский, спутник, водка. Если мы подведем итог этой краткой трактовке заимствованных слов, то подчеркнем, что при изучении заимствованных слов лингвист не может только лишь довольствоваться установлением источника, даты проникновения, семантической сферы, к которой принадлежит слово, и обстоятельств, которые сопровождают этот процесс. Это все крайне важно, но еще необходимо обратить внимание на изменения новой языковой системы, в которое заимствованное слово проникает в причины в самом слове, и, с другой стороны, искать изменения, вызванные новичком в английских словарях, когда он нашел свой путь в новый язык, он тем самым оттеснил некоторых из своих лексических и семантических соседей. В данном выше примере обсуждении мы попытались показать важность проблемы соответствия шаблонам, типичным для принимающего языка, и его семантическим потребностям.

Наш язык как раз-таки очень разнообразен. Русский язык не такой бедный или такой не такой жадный: он только принимает и ничего не отдает. Как раз наоборот. Русский язык готов со всеми делиться своими словами, но экспорт чаще идет не на Запад, а на Восток. Если сравним русский язык и казахский, например, то увидим, что в казахском языке очень много заимствований из русского. Кроме того, русский язык является посредником для очень многих слов, которые идут с Запада на Восток и с Востока на Запад [7]. Многих носителей языка раздражают именно недавние заимствования; английские слова воспринимаются едва ли не как враги русского языка. В ответ на это приведем слова профессора МГУ Марины Сидоровой: «Но кто здесь виноват? „Лэйаут“ и „воркаут“ абсолютно не виноваты. Здесь дело в общей культуре человека. В этом случае человеку просто не приходит на ум наше, русское слово.

И когда человек внедряет и пускает в ход новое слово, будь оно заимствованное или придуманное русское, он не может предсказать его судьбу. Есть очень хороший наглядный пример - первая русская „Арифметика“ Леонтия Магницкого [6]. Исследования показывают, что язык требует, как запоминания слов в нашем мозгу, так и их композиции в реальном времени: новое исследование обнаружило разницу между тем, как разные группы людей запоминают и извлекают слова. Люди принимают решения по-разному в зависимости от того, владеют ли они родным или вторым языком если мы запретим иностранные слова, мы просто-напросто остановим развитие языка. И вот тогда-то есть угроза, что мы начнем говорить на другом языке (например, на том же английском), ведь русский язык в этом случае не позволит нам выражать наши мысли полно и подробно. Иными словами, запрет на употребление иностранных слов ведет не к сохранению, а к уничтожению языка.

Некоторые заимствования действительно могут употребляться неудачно. Это не значит, что слово неудачное или неправильное, просто оно может быть употреблено не к месту. Например, читаем в газетной статье: «драматический рост безработицы». Как же определить - удачно или неудачно употреблено иноязычное слово? Нам на помощь придет словарь. Смотрим значение слова (фактически примеряем каждое значение, как одежду) [9]. Словарь дает нам четыре значения слова «драматический»:

1. к слову драма (драматический театр). Значение не подходит.

2. рассчитанный на эффект, напыщенный (драматическая пауза). Может ли рост безработицы быть напыщенным? Определение снова неверно.

3. напряженный, тяжелый, мучительный (драматический период жизни). Тоже что-то не то.

4. о тембре, голосе певца, певицы (драматический тенор). Явно не подходит.

Складывается ситуация, что даже с помощью словаря мы не можем выяснить, что же хотел сказать журналист. На самом деле этот человек просто взял похожее английское слово «dramatic», которое имеет одно из значений «разительный, впечатляющий». Как раз русские слова и надо использовать, а английское здесь совсем не к месту: в английском языке такое значение у слова «dramatic» есть, а в русском у слова «драматический»нет. Следует вывод, иноязычное слово в данном примере употреблено неудачно. Но это же вовсе не означает, что нужно срочно запретить употребление слова «драматический», не так ли?

Заимствованные слова имеют разную степень привлечения инородных слов. Например, есть слова, которые пришли из других языков, но стали в итоге не просто привычными, а родными, - это «кефир», «халат», «баня», «хата» и так далее. Мы давно привыкли к ним и думаем, что эти слова русские, не чужие. Так же есть иноязычные слова в нашем языке, без которых не обойтись, потому что они называют реалии современного технического, экономического, спортивного, политического и делового круга. При этом, если мы используем заимствования, мы не теряем своей самобытности, а, наоборот, адаптируем чужеродные слова под себя. Достаточно вспомнить 
словообразование, а именно такие приемы как суффиксы, приставки, глагольные формы. В итоге получаются новые русские слова! И это неплохо. Но к засилью в речи ненужных иностранных слов другие лингвисты и филологи относятся резко отрицательно [2].

Любая подмена неоправданна. Некоторый избыток иностранных слов в современной языковой жизни нашего общества ощущается явно. Настойчиво и порой назойливо они лезут в глаза и уши. Но хочется сказать, что исчезновение родного языка нам не грозит. Хороший и правильный русский язык может уйти с газетной полосы (хоть это и преувеличение, так как издания очень разные), из Интернета (хотя вряд ли), а также из некоторых сфер человеческой деятельности. Но он не уйдёт из современной художественной литературы, из многочисленных научных и научно-популярных изданий и что немало важно, из речи образованных людей.

Зададимся вопросом, почему не русский стал языком международного общения, а английский? Не из-за сложности - это точно! На это есть другие причины. А. Сперанская высказывается очень субъективную мысль: «Мы мало любим свой язык и плохо его знаем. Мы говорим о превосходстве: «Наш язык - самый богатый язык в мире!» - но это нелюбовь! Любовь, в моём понимании, это когда ты можешь процитировать русскую поэзию и прозу в достаточном объёме, чтобы иностранец, услышав, смог почувствовать и красоту русского слова, и его ценность для вас» [5].

Давайте немного пофантазируем! Сегодня многие заменяют слова смайликами или звуками. Может так получиться, что в будущем нам вообще не пригодится язык, и мы сможем общаться без него? Нет, обойтись без языка человек не сможет. Язык - это система знаков. И если знаки будут другими, то это приведёт к появлению нового языка. Конечно, очень обидно терять хорошо организованный и богатый язык. Без способности полноценно выражать свои эмоции мы деградируем. Вернёмся к тому, от чего ушли, - к древнему человеку.

Но разве не заслуживает уважения память поколений, которая запечатлена в русском слове? Неужели не важно его изучение и познание, знание, ставшее частью души миллионов людей, которые говорят на русском языке? Необходимо сохранение родной русской речи, защита и действенная забота о родном слове, забота о высоком уровне национальной речевой культуры [1]. Это задача каждого носителя русского языка - каждого из нас. Высокий интерес к родному языку, стремление освоить его систему и помочь совершенствоваться в знаниях и умениях владения родной речью поможет постичь тайны языка, его национальную самобытность, повысит культуру слова, а значит, и общую культуру. Бережливое отношение к русскому языку позволит сберечь духовную крепость нации, ее историческую память, сохранить русского человека в нравственном и в физическом смыслах.

\section{Зак^ючение}

Давайте подведем итоги нашей темы. Заимствования - закономерный путь развития русского языка, так как народ, т.е. носитель и творец языка, не живет совершенно изолировано. Часто в речевой ситуации такое заимствованное слово становится более престижным, чем русское. Чем легче язык усваивает интернациональную лексику, чем больше он пополняется за счёт включения в него всего того ценного, содержащихся в других языках, тем этот язык совершеннее и богаче.

Но существует, несколько, но! Если мы употребляем заимствованные слова, то мы должны четко понимать их значения. Заимствованные слова нужны только в том случае, если они лучше выражают главный смысл данного понятия или если их нельзя заменить русским словом.

Работая по данной теме, выясняется, что сегодня, на современном этапе наибольшее количество заимствований приходит в нашу речь из английского языка.

В дальнейшем мы намерены продолжить исследовать английские заимствования в русском языке, так как изучение процессов заимствований из английского языка представляет собой интерес в теоретическом и практическом плане. Англицизмы и американизмы в русском языке, история и перспективы, аспекты их употребления - проблемы весьма сложные, требующие дальнейшего изучения.

Следует четко понимать, что заимствование - это способ развития языка, который невозможно остановить! Ведь язык - это живое существо. Что-то в нем рождается, проживает всю жизнь, что-то уходит, а чтото остаётся навсегда. Каждое новое поколение вносит в язык свою лексику. Кто-то из сторонников относится к ней положительно, соответственно противники - отрицательно. Но полностью отрицать это явление мы конечно же не можем.

\section{ЛИТЕРАТУРА}

1. Адамчик В.В. Новейший словарь иностранных слов и выражений. Минск: «Современный литератор», 2007

2. Аникин А.Е., Корнилова И.А. Из истории русских слов. М.: Школа-Пресс, 2009 
3. Введение в языкознание. Хрестоматия. Сост.: Б.Ю. Норман и Н.А. Павленко. Под ред. А.Е. Супруна. Минск, «Вышэйш. школа», 1977.

4. Величко А.Р. 0 «русскости» русского языка наших дней. М.: Азбуковник, 2011

5. Володарская Ф.А.// Вопросы языкознания.- 2002.- № 4.— С. 102-104.

6. Краткий словарь иностранных слов /Сост. С.М. Локшина. - 8-е изд., стереотип. - М.: Рус. яз., 1985. - 352 с.

7. Крысин Л.П. Толковый словарь иноязычных слов.- М.: Эксмо, 2008

8. Русский язык и культура речи: Учебник для вузов/, и др. Под редакцией М., 2002

9. Свиренкова Г.А. «Англицизмы в современном русском языке» Режим доступа: https://urok.1sept.ru/articles/410377

10. Шарифуллин А.М.«Свое» и «чужое» в русском экспрессивном фонде // Русская речь, № 6, 2012

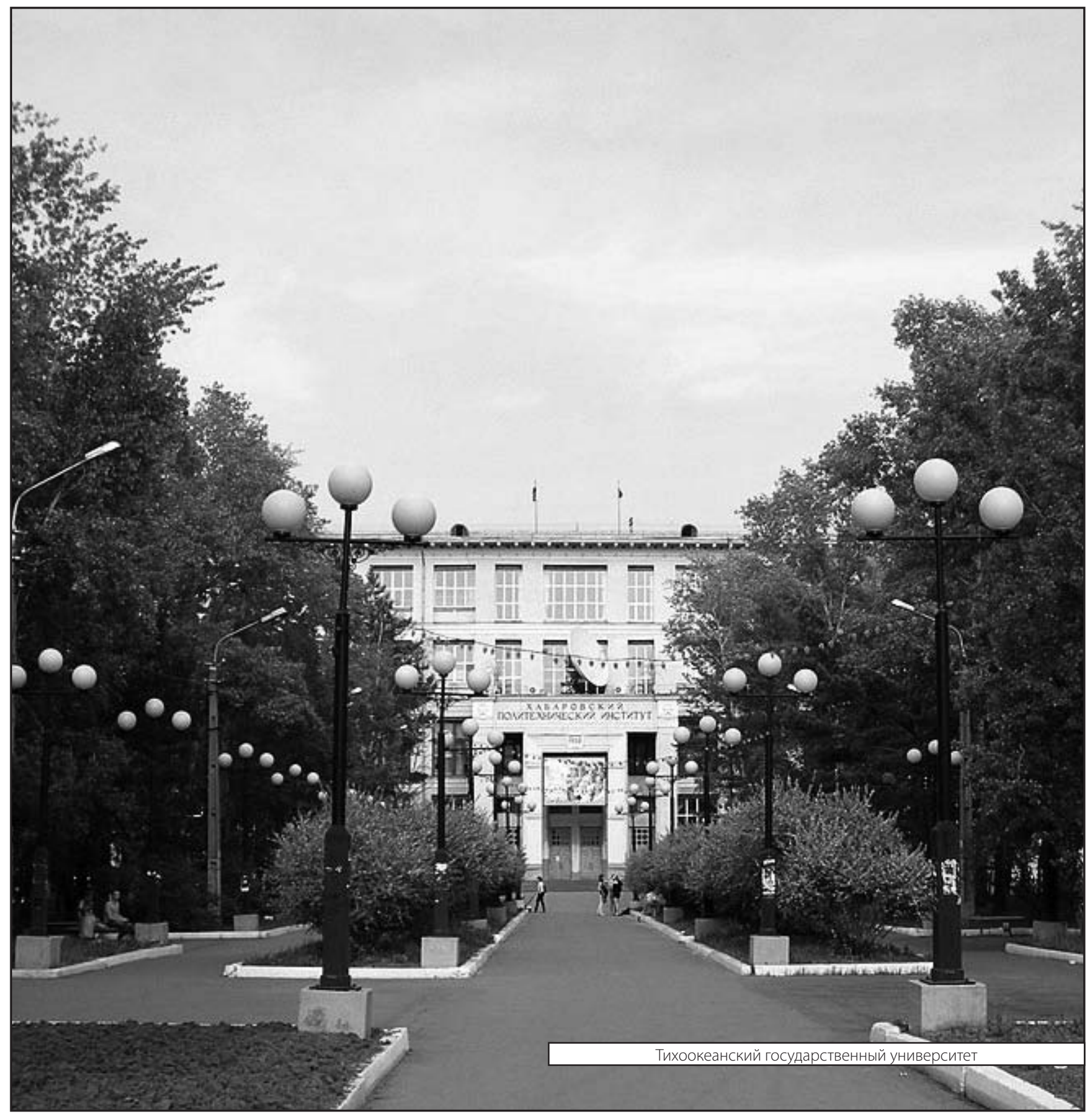

